\title{
NEW PRODUCT DEVELOPMENT AND FLAWED CAUSE-AND-EFFECT RELATIONS IN STRATEGY MAPS - study case -
}

Rainer Lueg, Leuphana University, Germany and University of Southern Denmark, Denmark

\author{
dx.doi.org/10.18374/EJM-21-1.4
}

\begin{abstract}
The case study deals with a division in an electronics-manufacturing corporation. The division follows a low-cost high quality strategy and uses target costing for new product development (NPD). The case illustrates how the division makes some mistakes in translating its insights from target costing into picking the right measures in the BSC. As a result, the BSC does not demonstrate the cause-and-effect relationships sought out in NPD. Several remedies relating to strategic alignment, a stricter customer focus as well as stronger application of people-related measures are suggestions how to deal with current problems. The case study offers the opportunity to discuss how the implemented strategy can be reflected by a code of conduct. The case study has been designed for teaching purposes and does not illustrate commendable or problematic corporate practices.
\end{abstract}

Keywords: Target costing; Balanced Scorecard; code of conduct; instructional case study. 